\title{
A Pluralidade Jurídica Diante das Transformações Institucionais na Contemporaneidade
}

\author{
Juliana Barbosa Torres \\ Doutoranda e mestre pelo Programa de Pós-Graduação \\ em Sociologia e Direito - PPGSD/UFF. Pesquisadora do \\ Laboratório Fluminense de Estudos Processuais - Lafep/ \\ UFF. Professora de Sociologia do Governo do Estado do \\ Rio de Janeiro. jubarbosatorres@yahoo.com.br
}

\section{Giselle Picorelli Yacoub Marques}

Doutoranda e mestre pelo Programa de Pós-Graduação em Sociologia e Direito - PPGSD/UFF. Pesquisadora do Laboratório Fluminense de Estudos Processuais - Lafep/ UFF. Professora assistente do curso de Direito da Universidade Federal Rural do Rio de Janeiro. gisellepicorelli@ hotmail.com

\section{Cibele Carneiro da Cunha M. Santos}

Doutoranda pelo Programa de Pós-Graduação em Sociologia e Direito - PPGSD/UFF. Pesquisadora do Laboratório Fluminense de Estudos Processuais - Lafep/UFF. Professora assistente da Universidade Federal Fluminense. cibele.carneiro@hotmail.com

\section{Resumo:}

Pensando as modificações institucionais ocorridas nas últimas décadas e a atual transformação da sociedade contemporânea, o presente estudo tem como objetivo analisar e questionar o protagonismo que 0 Direito e as instituições jurídicas ganharam diante das relações sociais e políticas na atualidade. 0 presente artigo propõe um debate sobre a crescente atuação do Direito na sociedade contemporânea, trabalhando, sobretudo, por meio da ótica dos meios alternativos de resolução de conflitos - um sistema plural de acesso à Justiça -, com destaque para a mediação. Importante destacar que tais meios não se postam em oposição ou exclusão do Poder Judiciário, servindo como uma possibilidade de redefinição e ampliação das possíveis vias para adequação na busca pelos direitos.

Palavras-chave: Pluralismo jurídico. Direito. Meios alternativos de resolução de conflitos. Mediação. Sociedade contemporânea. 


\section{The Legal Plurality Front of Institutional Changes in Contemporaneity}

\section{Abstract:}

Thinking about the institutional changes that have occurred in recent decades and the current transformation of contemporary society, the present study aims to analyze and question the role that Law and legal institutions have gained while facing social and political relations today. This article proposes a discussion about the growing role of Law in contemporary society, working, primarily, through the point of view of alternative means of dispute resolution - a plural system of access to justice -, with emphasis on mediation. It's important to emphasis that these means are not opposite and do not exclude the Judiciary, serving as a possibility of redefinition and expansion of possible ways to adjust the search for the rights.

Keywords: Legal Pluralism. Law. Alternative means of conflict resolution. Mediation. Contemporary society.

\section{Sumário}

1 Introdução. 2 Crise do judiciário. 3 Pluralismo jurídico. 4 Por uma solução adequada dos conflitos - por que a mediação? 5 Considerações finais. 6 Referências 


\section{INTRODUÇÃO}

A rápida e intensa expansão das instituições jurídicas nas últimas décadas não são, para Garapon (2001), uma questão de conjuntura e sim uma dinâmica das sociedades democráticas. "Nós não nos tornamos mais litigantes porque as barreiras processuais caíram. A explosão do número de processos não é um fenômeno jurídico, mas social” (Lieberman, 1981 apud GARAPON, 2001, p. 26). Nesse sentido, Garapon demonstra certo incomodo quanto ao "atual entusiasmo exagerado pela justiça". De acordo com o autor dar à justiça o papel de um poder onipotente capaz de abarcar todas as mazelas sociais subverte a própria justiça, fazendo com que esta perca seus princípios mais caros.

Ademais, junto ao fenômeno da "cultura da sentença” (Watanabe, 2007) - no qual a busca por uma decisão judicial tem como fundamento a pacificação do conflito - o Poder Judiciário vivencia aguda crise e apresenta contumaz ineficácia da tutela prestada. A mudança de mentalidade é premente, devendo-se buscar outros meios de abordagem dos conflitos, sendo a reflexão sobre o pluralismo do Direito de grande relevância.

Dentro desse contexto, os meios alternativos de resolução de conflitos, com destaque para a mediação, têm lugar como possibilidade de um "novo" mecanismo de desconstrução de conflitos, com a tentativa de possibilitar o diálogo e a ampliação da compreensão das partes em dissonância, transformando a situação adversarial em uma situação de cooperação, na busca da promoção do acesso à justiça de forma mais eficaz que a tradicional, ou apenas sendo mais uma opção dentro das existentes para os cidadãos, em termos de busca por meios de resolver suas controvérsias.

\section{CRISE DO JUDICIÁRIO}

A atualidade destaca uma crise no Poder Judiciário que clama por reformas estruturais e políticas. Essa situação tem origem na globalização política, social e cultural que a sociedade experimenta na contemporanei- 
dade. Como Anthony Giddens (1991) afirma, vivemos em uma época de total radicalização das instituições modernas, instituições essas que se encontram sem precedentes anteriores à sociedade moderna. Uma dessas é a diluição das barreiras entre as instituições sociais e políticas.

Essas transformações mostram o Estado em crise e, por vezes, até enfraquecido. Como a jurisdição é uma atividade estatal, natural que ela se encontre nesse cenário e seja motivada a transformar-se para melhor atender a essa "nova sociedade".

O enfraquecimento do Estado pode representar até perda da sua soberania, e, em especial, no tocante à jurisdição, e isso se verifica quando percebemos que ele se tornou incapaz de dar respostas céleres e qualitativas para os conflitos que lhe são apresentados. Perdeu, certamente, a efetividade em sua atuação. Para superar esse cenário, ele precisa modernizar suas estruturas. O tempo do processo judicial não é o tempo real imposto pela globalização econômica e cultural.

A sociedade mundial convive com uma enorme expansão da complexidade social e da contingência do processo decisório. Complexidade é o mesmo que pluralidade de alternativas. Contingência significa que se a decisão, hoje, recaiu sobre a hipótese " $x$ ", nada impediria que, legitimamente, tivesse recaído sobre a hipótese "y", ou que, no futuro, recaia sobre a via " $z$ ". Vale dizer, quanto mais complexa e contingente a sociedade, mais escassas as chances de decisões consensuais (diante da multiplicidade das escolhas) e mais nítidas as artificialidades que informam o processo decisório (dada sua contingência). Em razão dessas características, decidir equivale a fazer escolhas árduas, em curto espaço de tempo, sobre matérias não rotinizadas e com consequiências sociais imprevisíveis. Os temas da política se reproduzem nesse contexto (Campilongo, 2000, p. 83).

Cumpre ao sistema político tomar decisões que vinculam à sociedade. Ele faz isso por intermédio do seu papel legislativo ao elaborar normas para serem operacionalizadas pelo Direito. A partir das normas 
que lhe são apresentadas, o sistema jurídico desempenha a função de garantir as expectativas. $\mathrm{O}$ sistema político deve ser apresentado separadamente do sistema jurídico para que a democracia exista. Isso não significa, porém, dizer que eles não se “tocarão”. Muito pelo contrário, a decisão de um irá refletir no outro, por isso que, também, a crise de um implica na do outro. Se o judiciário não consegue ser efetivo na sua atuação, o papel político do Estado fica fragilizado.

Neste sentido, sobre a crise vivenciada pelo Judiciário e suas consequências, afirmam Ana Carolina Ghisleni e Fabiana Marion Spengler:

a crise jurisdicional está diretamente vinculada à crise estatal, haja vista o crescimento e a complexidade de conflitos sociais aliados à falta de estrutura física, tecnológica e financeira do Estado, o rebuscamento da linguagem jurídica, o acúmulo de processos, entre outros.

Nessa esteira, presencia-se uma crise da dogmática jurídica positivista que também é uma crise do Estado e, por conseguinte, do Poder Judiciário, assim como de todos os aplicadores do direito, em especial os juízes, cuja redefinição se faz urgente e necessária a fim de que se possa dar uma nova conotação ao direito, para que seja efetivamente mais justo (Ghisleni, Spengler, 2011, p. 24).

Diante dessa crise, a sociedade começa a pensar outras formas para suprir essa ineficácia do Estado para a solução dos conflitos. Isso não é um aspecto negativo, ao contrário, pode representar uma forma de emancipação e reforçar a cidadania. No tocante aos conflitos, surgem as formas alternativas de solução de controvérsias, ou, melhor dizendo, outras maneiras adequadas para dirimir o dissenso. Dentre elas, podemos citar a conciliação, a mediação e a arbitragem. No decorrer deste texto, cuidaremos mais especificamente da mediação. 
Atualmente, há uma grande preocupação em democratizar o processo judiciário defendendo a comparticipação dos atores envolvidos e o policentrismo (Nunes, 2011). Severas críticas são traçadas à figura do juiz solitário, único responsável pela decisão final acerca do conflito apresentado.

(...), se defende que o procedimento é constitutivo de todo o processo de decisão, de modo que, para o aqui defendido processualismo constitucional democrático, a comparticipação e o policentrismo são institutivos de um processo normativamente disciplinado pelos direitos fundamentais, que garantirá uma formação adequada dos provimentos, sem que estes possuam conteúdos fixos predeterminados ao se aplicarem as normas (princípios e regras). Tal procedimento respeitará e fomentará a participação e contribuição de todos os envolvidos nas esferas decisórias (Nunes, 2011, p. 147).

O que não podemos esquecer é que a utilização dos meios alternativos, em especial a mediação, privilegia, quase na totalidade, a participação dos envolvidos na decisão final do conflito. Destarte, apresenta-se este trabalho como uma contribuição para essa democratização tão propagada pelos juristas da atualidade. O que interessa é demonstrar como a participação ativa dos "consumidores" do direito pode desempenhar uma função relevante e de bons resultados na estratégia dos serviços legais inovadores (Campilongo, 2000, p. 23).

Garapon observa o direito conquistando cada vez mais o papel de "ligamento" e "ordenador" das atividades comunitárias ante a sociedade moderna. "Os juízes são chamados a se manifestar em um número de setores da vida social cada dia mais extenso. (...) O juiz é normalmente designado como árbitro de costumes, até mesmo da moralidade política” (Garapon, 2001, p. 24). 
De acordo com Garapon, o juiz também é uma referência para o indivíduo "perdido, isolado, sem raízes”, que, no confronto com a lei, procura algo de sua identidade. Para o autor, ninguém é “intocável” em relação à lei.

O apelo à justiça é de alcance geral (...). Essa nova sensibilidade traduz uma demanda moral: a espera de uma instância que nomeie o bem e o mal e fixe a injustiça na memória coletiva. (...) A justiça não pode mais se contentar em dizer o que é justo, ela deve ainda instruir e decidir, aproximar e guardar distâncias, conciliar e resolver, julgar e comunicar (Garapon, 2001, p. 25-26).

Nesse sentido, o autor afirma que a sociedade que se torna insegura em relação ao direito, tende a cada vez mais se judicializar. Sendo assim, para Garapon, o desafio da sociedade moderna está em estabelecer uma complementaridade entre justiça e democracia, buscando encontrar os meios de "dinamização da democracia pela justiça”. O autor ainda faz outro questionamento nesse sentido: "Como satisfazer ao mesmo tempo a aspiração à paz e à necessidade de uma autoridade?” (Garapon, 2001, p. 175).

É nesse sentido que o autor propõe uma "terceira via”, entre a dissolução do direito e a restituição das antigas formas tradicionais; que seriam as novas formas de justiça, em que aparecem espaços que estão "aparentemente independentes da justiça, mas nos quais ela não está ausente” (Garapon, 2001, p. 228).

Importante ressaltar que não se apresenta mais uma forma de garantir celeridade, mas sobretudo efetividade na solução dos conflitos. Diversas reformas processuais foram realizadas para isso, até a possibilidade de decisões em massa, como é o caso, no direito brasileiro, do procedimento para recursos repetitivos e o julgamento liminar de improcedência para conflitos que versem unicamente sobre a questão de direito, quando já houver decisão nesse sentido. Se, por um lado isso é bom para evitar decisões divergentes e garantir a justiça, por outro pode gerar exa- 
tamente o contrário. Assim, ao deixar para as partes a solução de seus conflitos, pode-se garantir um procedimento mais dialético e mais democrático. Lembremo-nos da preciosa lição de Aristóteles, segundo a qual a virtude está no meio termo.

O excesso de demandas judiciais pode nos levar a situações extremas, como a noticiada por Boaventura de Sousa Santos, que relata a gravidade da situação em Portugal com o número excessivo de demandas:

Em Portugal, a situação atingiu tal gravidade que alguns tribunais foram obrigados a fazer uma contingentação de entrada de processos, isto é, determinaram que uma dada empresa não poderia intentar mais de um certo número de ações judiciais por semana. Veja-se o paradoxo: enquanto se luta para que os cidadãos tenham mais acesso aos tribunais; nestes casos o que se procura é reduzir o acesso (SANTOS, 2007, p. 29).

Claro que não queremos chegar ao ponto de suprimir o acesso ao Judiciário, mas sim de que o processo distribuído não leve anos para ser solucionado pelo juiz togado se podemos pensar em solução mais digna por outros atores sociais. Afinal, a experiência nos mostra que nem sempre a solução dada pelo juiz da causa é a mais pacificadora.

Essa retirada do Judiciário para a solução dos conflitos já é experimentada em algumas situações específicas no Brasil, como a da Justiça Desportiva, Tribunal de Contas, Cade, mediação em causas de família e, mais recentemente, com o divórcio pelo Cartório (divórcio administrativo). A solução do conflito pelos próprios envolvidos pode ser muito mais benéfica do que se imagina, trata-se da Justiça coexistencial.

Neste sentido, e, em especial quando se fala em acesso à justiça, Cappelletti, afirma que “... há situações em que a justiça conciliatória (ou coexistencial) é capaz de produzir resultados que, longe de serem de 'segunda classe' são melhores, até qualitativamente, do que os resultados do processo contencioso...” (Cappelletti, 1994a, p. 90-91). 
Ademais, em relação tanto à adequação de procedimento quanto da resolução dos conflitos, e uma possível ineficácia da sentença judicial, também demonstra Cappelletti a possibilidade da utilização da justiça coexistencial quando diante de relações continuadas.

Entendo, com efeito, que em muitos aspectos da vida contemporânea o que mal se justifica é precisamente o caráter contencioso da relação, o qual deve ser, tanto quanto possível evitado ou atenuado. Isso é verdade sobretudo quando entre as partes subsistem relações duradouras, complexas e merecedoras de conservação. (...) A decisão judicial emitida em sede contenciosa presta-se otimamente a resolver relações isoladas e meramente inter-individuais; ela se dirige a um episódio do passado, não destinado a perdurar. A justiça coexistencial, pelo contrário, não visa a trancher, a decidir e definir, mas antes a 'remendar' (falei justamente de uma mending justice) uma situação de ruptura ou tensão, em vista da preservação de bem mais duradouro, a convivência pacífica de sujeitos que fazem parte de um grupo ou de uma relação complexa, à qual dificilmente poderiam subtrair-se (grifos no original) (Cappelletti, 1992, p. 133).

Uma das causas do excesso de demandas é a criação de novos direitos, sobretudo aqueles que visam a efetivar os direitos humanos. Paralelamente a essa criatividade jurídica temos a efetividade dos meios de comunicação de tornar possível o acesso à informação dos cidadãos e com isso aumentar a busca pela satisfação de sua tutela jurídica. Evidente, que isso é altamente benéfico, uma vez que a ignorância afasta a cidadania. A questão, no entanto, é que o tradicional modelo jurisdicional de uma lógica legal-racional não atende a essa demanda dos novos tempos. Faltam meios materiais, pessoais e até regulamentares para que o Estado cumpra sua função de dirimir conflitos de maneira célere e com qualidade. Definitivamente, o tempo do Judiciário não é o real.

Sendo assim, devemos buscar novos caminhos para que os sujeitos desses direitos subjetivos possam ver sua tutela satisfeita, ainda que fora dos domínios do Estado. Para isso, pensamos na mediação instituída pela 
vontade dos próprios envolvidos no conflito. Alguns conflitos que abrangem a parcela menos favorecida da população só são fomentados diante da complexidade burocrática do processo judicial, que, ao invés de aproximar a justiça dos cidadãos, faz com que o abismo cresça ainda mais.

Isso não significa descartar o Judiciário, mas relativizar seu monopólio. Não só a hipossuficiência de quem o busca, ou o excesso de demandas, mas também a complexidade dos "novos direitos" como, por exemplo, os direitos difusos e coletivos, impõe a necessidade de se pensar em outros meios adequados para a solução das controvérsias, priorizando a participação dos envolvidos, que são os sujeitos mais interessados numa solução efetiva, que ponha fim ao litígio de maneira definitiva e não apenas pontual. Esses anseios não significam que o Judiciário pode ser excluído, mas apenas que ele deve indicar novos caminhos no tratamento dos conflitos para que a população possa acreditar em seu papel importante na resolução de litígios.

O modelo tradicional da jurisdição estatal precisa ser revisto. Nas palavras da professora doutora Fabiana Marion Spengler:

Atualmente, ele (modelo conflitual de jurisdição) se caracteriza pela oposição de interesses entre as partes, geralmente identificadas com indivíduos isolados, e a atribuição de um ganhador e um perdedor, no qual um terceiro, neutro e imparcial, representado pelo Estado, é chamado a dizer a quem pertence o Direito. Esse modelo tem sido posto em xeque, fazendo com que a possibilidade de repensar a jurisdição readquira consistência, partindo da idéia do consenso e da jurisconstrução, sem intermediação de um terceiro entre as partes, conforme o modelo atual, de caráter triádico, no qual uma pessoa alheia intervém impondo uma decisão a partir da função do Estado de dizer o direito (2010, p. 115-116).

Assim, a dificuldade do judiciário em desempenhar sua atividade de solução de controvérsias possibilita essa reflexão acerca do verdadeiro papel e participação positiva dos destinatários desse serviço estatal. Pensa- 
mos que a emancipação dos sujeitos, chamando-os a construir o caminho para pôr fim ao litígio, seja uma forma eficaz de reforçar o sistema político democrático e superar essa crise.

\section{PLURALISMO JURÍDICO}

O pluralismo jurídico sempre esteve presente nas sociedades. A convivência de vários ordenamentos normativos pode ser visualizada desde a experiência da colonização, quando o direito dos colonizadores convivia com o dos colonizados, e mesmo antes, quando pensados no Direito do Estado e no Direito da Igreja. Ao falar em pluralismo jurídico, não se está referindo aos diversos diplomas normativos emanados do Estado, mas de diferentes seguimentos da sociedade civil com legitimidade para regular comportamentos além daquele. Essa tradição de se ter várias fontes normativas se mantém e na modernidade pode ser vista no processo de globalização.

De acordo Fabiana Marion Spengler,

De fato, a partir do processo de globalização, pode-se observar a hipervalorização do mercado, o que centrou a ação política de todos os países (industrializados ou não) num mesmo objetivo: estabilidade de preços, equilíbrio da balança, competitividade, privatização, desregulação. Diante de tal realidade, impossível obter, no plano legislativo, a criação ou recriação de condições de fomento à iniciativa econômica das partes de modo a realizar o mais amplamente possível a conquista de vantagens concorrenciais eliminando a interferência suscetível de frear o desenvolvimento. Em resumo: os Estados se dispõem a adotar normas favoráveis à arbitragem transnacional e muito liberais em termos de reconhecimento da validade de leis supraestatais com o intuito de se manter competindo. Nesse viés, pode-se observar que a globalização e suas consequiências são fatores determinantes para a necessária reconsideração do sistema jurídico clássico pensado para regular uma sociedade internacional dividida em Estados-nação (2010, p. 73). 
Por esse exemplo, pode-se perceber como em alguns pontos o monopólio do Estado para legislar representa uma barreira para o desenvolvimento. Deve-se, então, permitir que os próprios interessados escolham a maneira de regulamentar suas atividades de acordo com as suas necessidades. Foi o que aconteceu no setor privado com a utilização da Lex mercatoria, que se tornou fonte do Direito transnacional, representada pelos usos e costumes e as câmaras arbitrais internacionais e reconhecida pelos Estados como espécie de regulação. Isso demonstra que o sistema jurídico estatal é apenas uma espécie do gênero de Direito, inclusive para resolver conflitos.

O pluralismo jurídico nega o Estado como único ator no processo de criação do Direito. Outras fontes legítimas, ${ }^{1}$ diferentes do poder legislativo "oficial”, são encontradas na sociedade, como por exemplo, escola, igreja, sindicatos, núcleos familiares, etc. A legitimidade desses grupos sociais reside na esfera de consensualidade dos ideais, dos fundamentos, das crenças, dos valores e dos princípios ideológicos (...) (Wolkmer, 2007, p. 96)

Cumpre observar que a função de legitimar não se explica só como justificação do Direito e do Estado, mas como ação consensualizada destinada a produzir adesão e integração social. O processo de legitimação surge "não por temor ou obediência, mas porque os atores sociais reconhecem tal condição como boa e justa” (Wolkmer, 2007, p. 96).

Nessa perspectiva, estando o sistema jurídico inserido nas transformações da sociedade contemporânea, temos que a busca por um sistema plúrimo precisa ser precedida (i) do conhecimento e reflexão sociológicos, (ii) do autoentendimento dos atores sociais envolvidos e (iii) da participa-

1 "O grande desafio é resgatar, perante a sociedade, a autocompreensão dos cidadãos acerca da possibilidade que estes trazem em si de resolver seus próprios conflitos, sem necessitar de alguém que, de forma coercitiva e ostensiva, diga a eles o que é o direito, o que é o justo, o que é que eles devem crer ou esperar, o que eles querem para si próprios” (Hansen, 2011, p. 115). 
ção ativa dos concernidos, permitindo desenvolver normativas legitimadas pela participação da sociedade e que atendam à demanda da massa social de forma substancial.

Sobre este viés da tensão existente entre assentimento, aceitação, validez social e legitimidade das normas, bem afirma Habermas:

Em regra geral, o assentimento motivado racionalmente associar-se-á a uma aceitação empírica, ou seja, produzida pelas armas ou por bens materiais, numa crença na legitimidade cujos componentes não são simples de se analisar. Esses amálgamas, porém, são interessantes na medida em que constituem em indício de que não basta a entrada em vigor positivista das normas para assegurar duradouramente sua validez social. A imposição duradoura de uma norma depende também da possibilidade de mobilizar, num dado contexto da tradição, razões que sejam suficientes pelo menos para fazer parecer legítima a pretensa de validez no círculo das pessoas a que se endereça. Aplicado às sociedades modernas, isso significa: sem legitimidade, não há lealdade das massas (grifos no original) (1989, p. 82-83).

Ao contrário do que afirma a teoria positivista de Kelsen (2008), a legitimidade não é consequência lógica da legalidade da ordem jurídica posta pelo Estado. Para que seja legítima, a ordem deve inspirar valores de justo e bom para que tenha adesão dos destinatários. Eugen Ehrlich (apud Spengler, 2010, p. 83) afirma que o Direito é concebido como "produto espontâneo da sociedade", como "direito vivo", ou seja, como algo que decorre da vida concreta das pessoas. E assim, além de regular a vida delas, deve servir também para resolver seus conflitos. A legitimidade do Direito deve estar centrada no conjunto de valores compartilhados no espaço social preestabelecido de forma horizontalizada $a$ partir do aparecimento de novos sujeitos políticos e de suas lutas em prol da satisfação justa de suas reais necessidades (Wolkmer, 2007, p. 98). 


\section{POR UMA SOLUÇÃO ADEQUADA DOS CONFLITOS - POR QUE A MEDIAÇÃO?}

O conflito é um fato inerente a qualquer arranjo social. Nem sempre ele deve ser visto apenas negativamente. A divergência pode se mostrar extremamente saudável para o crescimento da sociedade, e a discussão revela ideias nunca pensadas que podem contribuir para melhorar a convivência entre as pessoas. Qualquer sociedade que seus integrantes (homens, mulheres, crianças) não tenham o mesmo status terá conflitos, porque as pessoas precisam convergir seus interesses para melhorar de vida. A distribuição desigual das chances de vida é um resultado das estruturas de poder (Spengler, 2010, p. 269).

É certo que alguns conflitos impedem o desenvolvimento e precisam ser resolvidos, ou, como preferir, precisam ser "tratados”. Para solucioná-los, o primeiro caminho que se cogita é o jurisdicional pelo Estado. De fato, o Estado monopoliza esse poder de resolver conflitos pelo uso de uma "força legítima". Ele detém autoridade para se impor coercitivamente aos litigantes dizendo qual será a solução para o litígio deles. Nesse arranjo social, o Estado possui o poder legítimo de controlar a vida de seus “súditos”. Dessa forma, o juiz, que integra o poder Judiciário, deve decidir o conflito evitando sua perpetuação, mas isso não significa, necessariamente, sua erradicação, porque a sua causa, na maioria das vezes, não é objeto de "instrução processual". O processo instaurado no judiciário preocupa-se com a consequência, ou seja, o dano causado, a ofensa ao direito subjetivo e o enquadramento deste ao direito objetivo posto por outro poder do Estado, sem investigar a sua causa.

A ideia de que cabe ao Judiciário resolver litígios é reducionista. O conflito é o resultado de uma cadeia muito complexa de interesses que ultrapassam a ordem normativa disponível para tal. Questões sociais, familiares, religiosas, dentre outras, permeiam o conflito e precisam ser enfrentadas para que ele possa ser resolvido definitivamente. Quando as 
partes apresentam seu conflito ao Estado, elas ficam inertes esperando por uma solução que diga quem é o vencedor, e se sujeitam a essa última palavra dada pelo juiz. Esse caminho, no entanto, não é capaz de frear a explosão de litigiosidade. Por isso, precisamos pensar em formas mais adequadas para o tratamento dos conflitos. Isso nos proporcionará, em certa medida, uma jurisdição mais eficaz.

Nesta direção, o ordenamento pátrio brasileiro permite, em algumas situações, a utilização de meios alternativos de solução de conflitos, também denominados de alternative dispute resolution $(A D R)$ - um sistema multiportas ${ }^{2}$ de acesso à Justiça - por entender tais meios mais eficazes em certas questões em debate. ${ }^{3}$ Este sistema permite a utilização de variados métodos de resolução de conflitos, ampliando as possíveis vias para adequação na busca pelos direitos.

${ }^{2}$ O termo sistema multiportas foi cunhado por Frank Sander (Multi-door Courthouse) em 1985, para designar a possibilidade de oferta e escolha de diferentes métodos de resolução de conflitos integrados ao Judiciário (Almeida, 2009, p.94). Insta salientar que tal termo, apesar de, originariamente, ser utilizado ao se tratar de métodos judiciais, entendemos perfeitamente possível a utilização de uma interpretação mais ampla, permitindo o uso também ao tratarmos de métodos extrajudiciais de resolução de conflitos por permitir o acesso à Justiça como efetivação de direitos.

${ }^{3}$ Como exemplos podemos citar: a Lei de Arbitragem - nº 9.307 de 23/9/1996; a Lei dos Juizados Especiais - n⿳o 9.099 de 26/9/1995 que instituiu a conciliação como regra; o projeto do novo Código de Processo Civil - PLS 166/10 que institucionaliza a medição intrajudicial, permitindo a criação de setores especializados de autocomposição; dentre outras normas que incentivam a composição amigável. No âmbito administrativo também a proposta da mediação se faz presente: a Lei no 9.427/96 que instituiu a Agência Nacional de Energia Elétrica e a Portaria nº 349/97 do Ministério de Minas e Energia estabelecem ações de competência da Superintendência de Mediação Administrativa Setorial - SMA/ANEEL para dirimir divergências entre os agentes do setor elétrico; existindo, inclusive, norma de organização da ANEEL (001), aprovada pela Resolução Normativa ANEEL nº 273/07, dispondo sobre os procedimentos - disponível em: <http://www.aneel.gov.br/>. Na Argentina, importante exemplo do uso da mediação surgiu com o estabelecimento da mediação obrigatória prévia nas ações judiciais - o Decreto 91/98 prevê a mediação oficial na Argentina, coexistindo a mediação oficial e privada. "Essa medida ocasionou uma verdadeira revolução cultural”. (Sarmento, 2005, p. 302). 
A opção pelo termo "meios alternativos de solução de conflitos” é decorrente da própria finalidade dos instrumentos utilizados, da alternatividade à atuação tradicional do Poder Judiciário e da busca pela dissolução da litigiosidade existente naquela relação. A proposta é de complementaridade à atuação do Poder Judiciário e não de exclusão deste. O que se pretende é ampliar o rol de possibilidades, sendo tais meios complementares e não concorrentes.

Assim, importante repisar que os meios alternativos de solução de conflitos não se postam em oposição ou exclusão do Poder Judiciário, servindo como instrumento complementar na abordagem dos conflitos.

As formas alternativas de resolução de conflitos não são renúncias ao sistema judiciário, mas sim uma redefinição de seus confins. Porém, é desviante pensar que tais mecanismos são remédios exclusivos à crise quantitativa da justiça, o que equivale a dizer que as disputas alternativas poderiam ser vistas de forma subalterna em relação aos mecanismos judiciários. A opção pela resolução extrajudicial não exclui a possibilidade da via jurisdicional, pois as partes podem recorrer ao Estado se não houver acordo ou se este for descumprido (Ghisleni; Spengler, 2011, p. 39).

Mediação, conciliação e arbitragem são consideradas a tríade básica de tais meios alternativos. São percebidas como tais pela possibilidade de ocorrerem de forma extrajudicial, ou seja, fora do arcabouço estatal. ${ }^{4}$ Cada

\footnotetext{
${ }^{4}$ Leia-se "controle estatal". O que se verifica na prática, contudo, é a utilização e a apropriação de tais meios pelo Poder Judiciário, uma vez que a conciliação, atualmente, tem sua prática totalmente vinculada aos Juizados Especiais, Estaduais ou Federais, e as audiências conciliatórias do processo judicial ordinário. Ademais, a mediação também parece seguir este caminho, pois a Resolução 125 do Conselho Nacional de Justiça e o projeto do Novo Código de Processo Civil tratam deste instrumento de forma já institucionalizada pelo Poder Judiciário, o que, na prática, também já vem ocorrendo, haja vista o exemplo do Núcleo de Mediação do Tribunal de Justiça do Estado do Rio de Janeiro.
} 
qual possui características e finalidade próprias, uma vez que, dependendo da natureza de cada litígio, determinado procedimento se apresenta mais adequado e, com isso, com maiores chances de efetividade.

Assim, alternativamente à jurisdição são apontadas a conciliação, a mediação e a arbitragem. Em todas, existe a participação de um terceiro. $\mathrm{Na}$ conciliação e na arbitragem, esse terceiro tem atuação ativa para resolver a divergência. Só na mediação podemos perceber um papel secundário do terceiro/mediador. Nesse caminho, os sujeitos ganham autonomia para encontrar, dentre várias opções, a melhor para resolver o seu conflito. Eles assumem o risco pela solução adotada e são responsáveis por ela. Essa autonomização dos sujeitos é uma forma de eliminar o conflito e não apenas decidi-lo, como caberia a um terceiro.

Essa autonomia é possível porque na mediação se busca uma "justiça de proximidade”, restaurativa, e não declarar quem é vencedor e quem é perdedor. Não se reduz o processo de tratamento de conflitos ao código binário ganhar/perder. Ambos são vencedores ao superar o conflito. Essa é uma das qualidades da mediação. Dessa forma, todos ganham, podendo, assim, fortalecer as relações democráticas entre os agentes sociais.

Importante destacar que:

Para que todos esses métodos de resolução de disputas possam ser postos em prática, contudo, o primeiro passo é deixar de considerar o conflito um evento social patológico, um mal a ser curado, para vê-lo como um fenômeno fisiológico, muitas vezes positivo. Isso significa abrir mão da lógica processual judiciária de ganhador/perdedor para passar a trabalhar com a lógica ganhador/ganhador desenvolvida por outros meios de tratamento (dentre os quais a mediação), que auxiliam não só na busca de uma resposta consensuada para o litígio, como também na tentativa de desarmar a contenda, produzindo, junto as partes, uma cultura de compromisso e participação. Nesses casos, não há um ganhador ou um perdedor: ambos são ganhadores (Spengler, 2010, p. 300). 
O processo judicial coloca as partes distantes, fomentando suas diferenças e controvérsias. A participação delas é mínima, e a manifestação feita pelos advogados. A notícia nunca é igual ao fato. O que vem para os “autos”, portanto, nem sempre expressa o que as próprias partes queriam dizer. Na mediação pode haver a participação de advogados das partes, mas essa ganha um caráter acessório. $\mathrm{O}$ objetivo da mediação não é chegar a um produto do tipo sentença, ou acordo, mas precipuamente tratar aquela litigiosidade em profundidade. Ela é vista como "ética da alteridade”, por se preocupar com o universo do "outro" sem se impor, sem dominações. Busca-se o respeito ao espaço alheio. $\mathrm{O}$ resultado se mostrará como consequência, apenas. É uma autêntica autocomposição.

A escolha pela mediação consiste na crença de que só ela é capaz de resgatar os canais de comunicação entre as partes outrora destruídos pelo conflito negativo. É uma lógica de reconstrução, baseada no respeito aos valores da sociedade. É preciso ver o conflito de várias formas, por diversos “olhares”. Esse meio de solução, e não de decisão, sobre os conflitos garante aos envolvidos a emancipação para permitir essas novas formas de percepção do dissenso.

Sem o objetivo de adentrar nas questões absolutamente técnicas da mediação, se torna importante destacar que a mediação diferencia do processo jurídico devido ao fato de que nesta são os atores sociais envolvidos que buscam desconstruir o conflito através do diálogo e da identificação do conflito real. Porém, não se nega o fato de que, mesmo sendo a mediação um meio alternativo de resolução de conflitos, se faz necessária uma regulamentação própria que fica a cargo do mediador ou de uma equipe de mediadores. ${ }^{5}$

${ }^{5}$ A equipe que participa do processo de mediação varia de acordo com o programa ao qual esteja associada, geralmente se conta com uma equipe de quatro pessoas (dois mediadores e dois observadores), em algum lugares exija-se formação jurídica (como acontece na mediação judiciária em Buenos Aires na Argentina) e em outros se preza por uma equipe interdisciplinar (composta por juristas, psicólogos, assistentes sociais, etc.) 
A função de quem assume o papel de mediador é a de viabilizar o diálogo entre as partes, tendo que inicialmente, explicar sobre a mediação e seus princípios fundamentais. A pessoa que assumi o papel de mediador é o fio condutor do diálogo entre as pessoas que buscam solucionar seus conflitos. Cabendo ao mediador não mais que auxiliar a conversa e manter um ambiente propício e dosado (em relação aos ânimos envolvidos), buscando assim, estabelecer um diálogo favorável.

Remo F. Entelman utiliza as teorias do sociólogo Georg Simmel sobre a natureza do conflito humano (Entelman, 2009, passim), em especial em relação ao papel do "terceiro no conflito". Entre os "tipos” de terceiros envolvidos em um conflito, Simmel (1950) analisa o "terceiro que participa da resolução do conflito”, ${ }^{6}$ mas não está envolvido nele; são os chamados "terceiros imparciais".

Para Entelman, esse modelo do "terceiro imparcial" se encontra bem-retratado no papel do mediador. Dentro dessa categoria de terceiros que atuam na resolução do conflito, está também o juiz, porém a diferença absoluta entre o mediador e o juiz é que o segundo é imposto a pelo menos uma das partes envolvidas.

A semelhança entre o papel do mediador e do juiz na resolução dos conflitos é que ambos atuam em processos complexos e relativamente demorados, nos quais participam as partes envolvidas. Para Entelman, porém, a grande diferença entre as duas funções é que o mediador é associado com a ideia de autonomia das partes.

Nas palavras do autor,

Un caso típico de esta subcategoría de tercero interviniente es el mediador que, aunque no resuelve el conflicto, colabora con las partes. Una muestra de esta importante distinción es que sean cuales sean las

${ }^{6}$ Cf. Simmel, Georg. The sociology of Georg Simmel., Editado e traduzido por Kurt Wolf. Nova York: Free Press of Glincoe, 1950. 
características que se atribuyan al mediador, el principio de autonomía, esto es, la idea de que la resolución depende de las partes es un elemento esencial de su actuar (Entelman, 2009, p. 138).

De acordo com o autor, o mediador é um facilitador de comunicações, e sendo assim, pode dialogar com mais facilidade com ambos os atores envolvidos e entender todos os temas ao redor do impasse. Ele pode transmitir para as partes impressões que cada uma tem da outra, e assim, criar um campo mais propício para se debater o conflito.

Nesse sentido, a atuação do mediador precisa ser ao mesmo tempo perspicaz e suave, pois o mediador, ao exercer sua função, precisa agir de forma que ele tenha controle sobre os ânimos envolvidos, criando um ambiente de empatia sem que interfira nas decisões e propostas dos atores. Sua função seria atuar como um catalisador de emoções que possa ajudar os envolvidos a "traduzirem" seus sentimentos, fazendo com que apareçam os verdadeiros interesses de cada parte.

Sobre a necessidade de se buscar esse terceiro imparcial para auxiliar na solução de conflitos, Humberto Dalla Pinho avalia que,

(...) a tendência natural das pessoas é tentar resolver o problema sozinhas, sem o auxílio de terceiros. Por vezes, contudo, tal estratégia acaba por tornar o conflito ainda mais intenso e afasta a solução que não pôde ser enxergada pelas partes, dado o seu envolvimento emocional (2008, p. 10).

Para Pinho (2008, passim), é o conflito que delimita a amplitude do trabalho que o mediador desenvolve. A mediação não pode ser confundida com um tratamento terapêutico, pois esta não possui a intenção e objetivo do mesmo. Embora o objetivo seja a busca de um diálogo esclarecido ocasionando consequente compreensão do conflito pelas partes, e ser 
interessante que o profissional atuante na mediação tenha conhecimento em Psicologia, existe um limite na intervenção, que deve ser respeitado sob pena de se perder o foco e alongar o processo.

No caso específico brasileiro existe ainda outro fator a ser adicionado na atividade de mediador, que é o de instruir os participantes sobre o processo de mediação, explicando, além das normas gerais do procedimento, seus objetivos e inspirações. De acordo com o autor, é justamente o fato de o medidor não propor soluções que é a novidade do processo em nosso país. Esse fato faz com que a mediação seja um processo muito mais dinâmico do que outros, como a conciliação, por exemplo (Almeida, 2008).

\section{CONSIDERAÇÕES FINAIS}

Como já ressaltado anteriormente, buscou-se trabalhar aqui a ideia de encontrar um intermediário entre as formas tradicionais de justiça e a diluição total desta. Como destaca Garapon (2001), a mediação se caracteriza pela grande liberdade que oferece, porém essa não é total, havendo sempre uma espécie de protocolo a ser cumprido, variando de acordo com cada programa de mediação.

Também se trabalha com a ideia de que a mediação não exclui o Judiciário e suas instituições; é mais uma "porta”, uma opção de acesso aos meios de resolução de conflitos, opção essa defendida aqui como um meio que busca emancipação dos agentes sociais ante a resolução de seus próprios conflitos, devolvendo às partes envolvidas o protagonismo que "perdem" diante do processo no Judiciário. Destaca-se que a mediação busca uma adequação a determinados tipos de relações, em especial às que as partes desejam e necessitam que sejam continuadas, como relações familiares, de vizinhos, etc. 


\section{REFERÊNCIAS}

ALMEIDA, Diogo Assumpção Rezende de. Da mediação incidental. In: DALLA, Humberto. Teoria geral da medição - a luz do projeto de Lei do Direito Comparado. Rio de Janeiro: Editora Lumen Júris, 2008.

ALMEIDA, Tânia. Mediação e conciliação: dois paradigmas distintos, duas práticas diversas. In: CASELLA, Paulo Borba; SOUZA, Luciane M. de (Coord.). Mediação de conflitos. Belo Horizonte: Fórum, 2009. p. 93-102.

CAMPILONGO, Celso Fernandes. O Direito na sociedade complexa. São Paulo: Max Limonad, 2000.

CAPPELLETTI, Mauro. Algunas reflexiones sobre el rol de los estudios procesales en la actualidad. Revista de Processo, ano 16, n. 64, p. 143-157, out./ dez. 1991.

. Problemas de reforma do processo civil nas sociedades contemporâneas. Revista de Processo, ano 17, n. 65, p. 127-143, jan./mar. 1992.

Os métodos alternativos de solução de conflitos no quadro do movimento universal de Acesso à Justiça. Revista de Processo, São Paulo, n. 74, ano 19, p. 82-97, abr./jun. 1994a.

La dimensione sociale: l'accesso alla giustizia. In: Dimensioni della giustizia nelle società contemporenee. Bologna: Mulino, 1994b. p. 71-102.

; GARTH, Bryant. Acesso à justiça. Tradução Ellen Gracie Northfleet. Porto Alegre: Fabris, 1988.

ENTELMAN, Remo F. Teoría de Conflictos - Hacia un nuevo paradigma. Barcelona: Gedisa, 2009.

GARAPON, Antonie. O juiz e a democracia. Rio de Janeiro: Revan, 2001.

GHISLENI, Ana Carolina; SPENGLER, Fabiana Marion. Mediação de conflitos a partir do Direito Fraterno. Santa Cruz do Sul: Edunisc, 2011.

GIDDENS, Anthony. As consequências da modernidade. São Paulo: Editora Unesp, 1991.

HABERMAS, Jürgen. Consciência moral e agir comunicativo. Tradução Guido A. de Almeida. Rio de Janeiro: Tempo Brasileiro, 1989.

Direito e democracia: entre facticidade e validade. Tradução Flávio Beno Siebeneichler. 2. ed. Rio de Janeiro: Tempo Brasileiro, 2010. Vol. I.

HANSEN, Gilvan Luiz. A resolução de conflitos no Estado Democrático de Direito: uma perspectiva Habermasiana. In: FACHIM, Zulmar; BANNWART JÚNIOR, Clodomiro José (Coord.). Direito e Filosofia - diálogos. Campinas: Editora Millennium, 2011. p. 99-120. 
KELSEN, Hans. Teoria pura do Direito. 8. ed. São Paulo: Martins Fontes, 2008. NUNES, Dierle José Coelho. Processo jurisdicional democrático - uma análise crítica das reformas processuais. Curitiba: Juruá, 2011.

PINHO, Humberto Bernardina Dalla. Teoria geral da medição - a luz do projeto de lei do Direito Comparado. Rio de Janeiro: Editora Lumen Júris, 2008.

SANTOS, Boaventura de Sousa. Para uma revolução democrática da justiça. São Paulo: Cortez Editora, 2007.

SPENGLER, Fabiana Marion. Da jurisdição à mediação. Por uma outra cultura no tratamento de conflitos. Ijuí: Ed. Unijuí, 2010.

SARMENTO, Roselaine dos Santos. Mediação familiar: um meio altamente eficaz de acesso à justiça. In: BASTOS, Eliene Ferreira; SOUZA, Asiel Henrique de (Coord.). Família e jurisdição. Belo Horizonte: Del Rey, 2005. p. 285-306.

SIMMEL, Georg. The sociology of Georg Simmel., Editado e traduzido por Kurt Wolf. Nova York: Free Press of Glincoe, 1950.

WATANABE, Kazuo. Acesso à justiça e sociedade moderna. In: GRINOVER, Ada Pellegrini; DINAMARCO, Cândico Rangel; WATANABE, Kazuo (Coord.). Participação e processo. São Paulo: RT, 1988. p. 128-135.

A mentalidade e os meios de solução de conflitos no Brasil. In: GRINOVER, Ada Pellegrini; WATANABE, Kazuo; LAGRASTA NETO, Caetano (Coord.). Mediação e Gerenciamento do Processo. São Paulo: Atlas, 2007. p. 6-10.

WOLKMER. Antônio Carlos. Pluralismo, justiça e legitimidade dos novos Direitos. Revista Sequência, n. 54, p. 96, jul. 2007.

Recebido em: 9/8/2013

Aceito em: 11/9/2013 